\title{
EFFECT OF SUGAR FOOD PRODUCTS ON THE INTEGRITY OF TINPLATE CONTAINERS
}

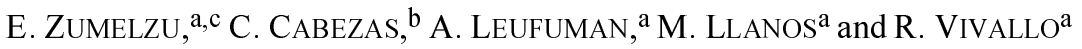 \\ a Instituto de Materiales y Procesos Termomecánicos Universidad Austral de Chile, \\ Casilla 567, Valdivia. Chile \\ ${ }^{\mathrm{b}}$ Instituto de Química Universidad Austral de Chile, Casilla 567, Valdivia. Chile
}

(Received: 16 June 1999; accepted: 15 March 2000)

The behavior of electrolytic tinplate coated with gold- and aluminum-plated sanitary lacquers employed to contain sugar food products was studied. Susceptibility to corrosion by electrochemical measurements and surface deterioration by scanning electron microscopy were also evaluated. The results showed the importance of an adequate selection of tinplate/lacquer to contain sugar food products and prevent contamination by ionic dissolution as a consequence of can corrosion.

Keywords: tinplate, sugar food product, corrosion, contamination, quality

When food preservation becomes necessary, knowing the functionality or behavior of the food/canning system is of most importance in order to keep the nutritious qualities and to avoid contamination by materials composing the container (KAMM et al., 1988; ZUMELZU \& CABEZAS, 1995).

However, different corrosion phenomena affecting the metal container are well known, these are progressive processes of no easy detection which in practice are the main source of canned-food alterations (HARRISON \& LANDRIAULT, 1990). These problems lead to rejection of canned foods, because of decoloration, smells, changes in the organoleptic characteristics, etc., causing economic losses and damaging potential markets (ZUMELZU \& CABEZAS, 1996).

Electrolytic tinplate still holds as a material displaying physical and economic advantages for its use in canned foods, but only if adequate materials are chosen for aggressive food products.

\footnotetext{
${ }^{\mathrm{c}}$ To whom the correspondence should be addressed. Fax: 56-63-221033;

e-mail:ezumelzu@valdivia.uca.uach.cl
} 
Tinplate is a complex, heterogeneous, stratified solid, constituted by wrought iron, $\mathrm{FeSn}_{2}$, free tin, and chrome. Each of the above-mentioned layers has a specific objective such as providing mechanical strength, moderating the corrosion processes, extending the useful life of cans, giving resistance to the medium and finally, the sanitary lacquer coating prevents contact between tinplate and the food product (ZuMELZU \& CABEZAS, 1995).

Lacquer causes a radical change in the nature of food product/tinplate interactions, since it modifies the free metal surface share (tin and steel) with respect to that observed in tinplate without protective layers.

It has been found that the weakness of the protection system of tinplate is essentially caused by discontinuities on the metal and organic surfaces (PATTIASINA \& HERTEGH, 1992) normally facing the action of aggressive electrolytic media. The incorporation of metal residues in food (i.e., tin, iron and chrome) is a consequence of the more generalized corrosion processes of tinplate. The former is also aggravated because foods are highly complex in composition, including a number of substances capable of influencing the corrosion processes of tinplate, either accelerating or inhibiting them (HELWIG \& BIBER, 1990).

In the particular case of sugar media, mainly those relating to fruit juices and fruits as a whole (peaches, pears, cherries, etc.), it has been determined that they can cause corrosion because of their acidic nature, which is a critical factor in the behavior of the product against tinplate. Therefore, the use of an adequate protective lacquer is of prime importance, since it will lead to increase the corrosion resistance against fruits and vegetables, sulfurs both in the can and the product when this contains sulfuretted proteins, and also reduces the decolorating action of tin on certain fruit pigments.

In this connection, the present work studies the performance of three different types of canning tinplates, coated by two kinds of sanitary lacquers, in order to characterize and evaluate the effect of sugar products on the tinplate/lacquer system and quality of canned foods. Specifically, the corrosion density and corrosion potential, using a sugar product as electrolyte or solution, are quantified. In addition, the morphological changes and interactions taking place at a microstructural level on the lacquered tinplates are characterized.

Hence, this shows the importance of selecting adequate materials for aggressive canned food products in order to preserve the original characteristics of food and minimize ion contanimation originating from the deterioration by corrosion. 


\section{Materials and methods}

The electrolytic tinplates selected for canning had different tin weight platings on both faces. The manufacturing of tinplate involves metal electrodispersion, coating with a lacquer using a roller, and drying at $210^{\circ} \mathrm{C}$, the plating being a coating of gold and aluminum dispersed on the polymer forming a layer, and their characteristics are given in Table 1.

Table 1

Characteristics of lacquered tinplates

\begin{tabular}{|c|c|c|c|}
\hline Parameter & Tinplate 1 & Tinplate 2 & Tinplate 3 \\
\hline Thickness (mm) & 0.21 & 0.23 & 0.23 \\
\hline Hardness (Rc 30T) & 58.3 & 57.8 & 57.6 \\
\hline \multicolumn{4}{|l|}{ Tin weight $\left(\mathrm{g} \mathrm{m}^{-2}\right)$} \\
\hline *Top face & 6.30 & 6.33 & 6.36 \\
\hline *Lower face & 3.36 & 3.50 & 3.78 \\
\hline \multicolumn{4}{|l|}{ Alloy layer $\left(\mathrm{g} \mathrm{m}^{-2}\right)$} \\
\hline *Top face & 1.30 & 1.30 & 1.31 \\
\hline *Lower face & 1.24 & 1.22 & 1.20 \\
\hline D.O.S. Oil $\left(\mathrm{mg} \mathrm{m}^{-2}\right)$ & 6.90 & 6.90 & 6.97 \\
\hline \multicolumn{4}{|l|}{ Coating $\left(\mathrm{g} \mathrm{m}^{-2}\right)$} \\
\hline *Gold plating 3.45 & 3.45 & 4.0 & 1.30 \\
\hline *Aluminum plating & 7.35 & 3.0 & 5.63 \\
\hline
\end{tabular}

Two types of epoxyphenolic lacquers applied to tinplate with different platings (i.e., gold or aluminum), which is a standard procedure in canned food products, were used and evaluated as indicated in Table 2 . The tinplate manufactured by the steel mill, which is later lacquered for the production of food containers, was cut into $25 \mathrm{~mm}$ disks. Then, these disks were rinsed using deionized water and placed on the sample holder to act as work electrodes in the electrochemical measurements.

The electrolytic medium used, representative of sugar products currently found in canned fruits, is indicated in Table 3. The components were dissolved in bidistilled water and the $\mathrm{pH}$ was adjusted to 40 using 0.1 mol sodium hydroxide, at $20^{\circ} \mathrm{C}$. Electrochemical measurements were all made in a sugar medium used as electrolyte, keeping it deaerated in a nitrogen environment and without oxygen. A standard cell (MANHEIM \& PASSY, 1982) with a platinum auxiliary electrode, a reference calomel electrode and a tinplate, lacquered disk as work electrode were used. Perturbations of the system were measured by means of an AFRD4 potentiometer. 
Table 2

Characteristics of sanitary lacquer

\begin{tabular}{lcc}
\hline Type & $\begin{array}{c}\text { Gold plating } \\
\text { epoxyphenolic }\end{array}$ & $\begin{array}{c}\text { Aluminum plating }^{\mathrm{a}} \\
\text { epoxyphenolic with Al } \\
\text { pigments }\end{array}$ \\
\hline Viscosity (seconds \#4 Ford Cup at $\left.25^{\circ} \mathrm{C}\right)$ & 100 & 110 \\
Specific gravity $\left(\mathrm{g} \mathrm{cm}^{-3}\right)$ & 0.961 & 0.966 \\
Percentage of solids $(\%)$ & 35.5 & 34.0 \\
Ignition point $\left({ }^{\circ} \mathrm{C}\right)$ & 24 & 21 \\
\hline
\end{tabular}

${ }^{a}$ Lacquers manufactured by Blundell Renner S.A. under I.C.I. paints licence.

Aluminum code: 643-E--246 and gold code: 642-E-345.

Table 3

Composition of synthetic medium prepared to simulate sugar products (pears syrup)

\begin{tabular}{ll}
\hline Component & Amount \\
\hline Citric acid & $1.0 \mathrm{~g} \mathrm{l}^{-1}$ \\
Malic acid & $1.0 \mathrm{~g} \mathrm{l}^{-1}$ \\
Tin chloride (II) & $50 \mathrm{ppm}$ \\
Sucrose & $50 \mathrm{~g} \mathrm{l}^{-1}$ \\
Fructose & $50 \mathrm{~g} \mathrm{l}^{-1}$ \\
Glucose & $50 \mathrm{~g} \mathrm{l}^{-1}$ \\
adjusted by $\mathrm{NaOH}$ to $\mathrm{pH} 4.0$ at $20^{\circ} \mathrm{C}$ & \\
\hline
\end{tabular}

The stabilization potentials were recorded once a constant potential between the work and reference electrodes was observed. Corrosion current densities were determined by means of the Butler-Volmer model for the data obtained with overpotentials ranging from $\phi 100 \mathrm{mV}$ and $\phi 500 \mathrm{mV}$ with respect to the calomel electrode, and after scannings at $0.25 \mathrm{mV} \mathrm{s}^{-1}$.

The characterization and microstructural evaluations of surface changes on the tinplate/lacquer system, caused by the sugar electrolyte, were carried out by scanning electron microscopy techniques (SEM) using a Nanbolab 2000 and Kevex microprobe. 


\section{Results and discussion}

The characterization of microconstituents composing the different substrates of electrolytic tinplates used in canning was performed by EDAX microanalyses, as shown in Fig. 1. The R-X scattered energy spectrum profiles on the tinplate surface qualitatively detect $\mathrm{Fe}, \mathrm{Sn}$, and $\mathrm{Cr}$, which are essential elements for the corrosion resistance of tinplate and allow to avoid dissolution into the sugar solution of foods.

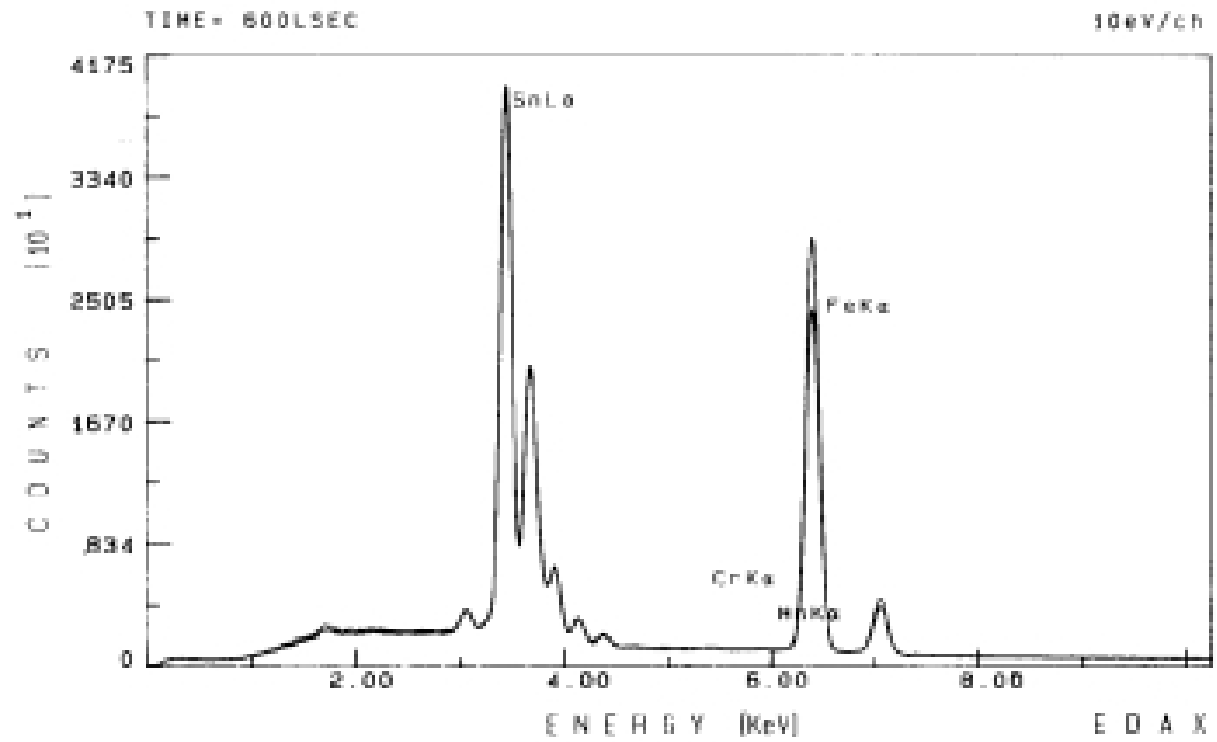

Fig. 1. Surface characterization of tinplate 1 (EDAX)

The results of electrochemical trials for the corrosion potential range of tinplates with gold and aluminum plating are indicated in Table 4 . Tinplate 3, with the lowest potential, presents less surface deterioration when using aluminum plating in sugar medium (Fig. 2). The experimental corrosion potential range determined was between $-708 \mathrm{mV}$ to $-433 \mathrm{mV}$, depending on the lacquer type. The potentials of tinplates 1 and 2 , coated with aluminum lacquer, approximate those of base steel, while the one corresponding to Tinplate 3 is very close to that observed in tin. On the other hand, all corrosion potential figures of tinplates coated with a gold lacquer are closer to tin. 
Table 4

Corrosion potential ranges of a tinplatellacquer system in a sugar medium

\begin{tabular}{|c|c|c|c|c|c|c|}
\hline \multirow[t]{2}{*}{ Tinplate } & \multirow[t]{2}{*}{ Lacquer } & \multicolumn{5}{|c|}{ Corrosion potential $\mathrm{mV}$ (CSE) } \\
\hline & & -750 & -650 & -550 & -450 & -350 \\
\hline \multirow[t]{2}{*}{ Tinplate 1} & Aluminum & & & & & - \\
\hline & Gold & & $\mathrm{OO}$ & & & \\
\hline \multirow[t]{2}{*}{ Tinplate 2} & Aluminum & & & & & $\varnothing \varnothing$ \\
\hline & Gold & \multicolumn{5}{|c|}{$\square \square$} \\
\hline \multirow[t]{2}{*}{ Tinplate 3} & Aluminum & $\diamond$ & & & & \\
\hline & Gold & \multicolumn{5}{|c|}{$\Delta \Delta$} \\
\hline
\end{tabular}

Symbols represent range of corrosion potential behavior

Note:The six symbols in this table (-, OO, $\varnothing \varnothing, \square \square, \diamond \diamond, \Delta \Delta)$ represent the corrosion potential behavior values, experimentally obtained, which range from -750 to $-350 \mathrm{mV}$

As shown in the table above, the gold lacquer for tinplate 1 has a value ranging from -650 to $-600 \mathrm{mV}$; tinplate 3 , with an aluminum lacquer, showed a value ranging from -750 to $-700 \mathrm{mV}$ approximately

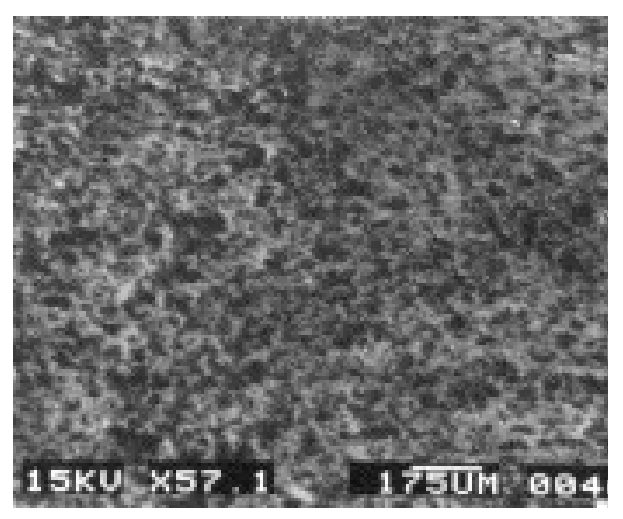

Fig. 2. Homogeneous surface attack by sugar solution on tinplate 3 having aluminum plating. Micropores penetrating into the protection lacquer (SEM X 57.1)

Table 5 shows the corrosion density ranges according to tinplate and plating. All aluminum coated tinplates, showed corrosion current densities lower than those observed in gold coated tinplates. Tinplate 1 exhibited the lowest corrosion speed and Tinplate 3 the highest. Concerning gold plated tinplates, Tinplate 1 was still the one showing the lowest current density, but Tinplate 2 turned out to be the one with the highest. 
Table 5

Corrosion density ranges of a tinplate/lacquer system in a sugar medium

\begin{tabular}{|c|c|c|c|c|c|c|}
\hline \multirow[t]{2}{*}{ Tinplate } & \multirow[t]{2}{*}{ Lacquer } & \multicolumn{5}{|c|}{ Corrosion density $\left(\mu \mathrm{A} \mathrm{cm}^{-2}\right)$} \\
\hline & & 0 & 2 & 4 & 6 & 8 \\
\hline \multirow[t]{2}{*}{ Tinplate 1} & Aluminum & - & & & & - \\
\hline & Gold & & & $\mathrm{OO}$ & & \\
\hline \multirow[t]{2}{*}{ Tinplate 2} & Aluminum & $\varnothing \varnothing$ & & & & \\
\hline & Gold & & & & & $\square \square$ \\
\hline \multirow[t]{2}{*}{ Tinplate 3} & Aluminum & $\Delta$ & & & & \\
\hline & Gold & & & & & \\
\hline
\end{tabular}

Symbols represent range of density behavior

Note: Symbols in this table are interpreted in the same way as explained in Table 4

The corrosion type encountered in all lacquered tinplates was mostly caused by pitting, starting as a series of micropores located on the surface of the lacquer exposed to the sugar medium, growing later into the tin layer and developing sometimes as localized detinning.

The aluminum plated samples developed pores of elevated walls, with a larger height-diameter ratio when compared to gold-plated tinplate. Therefore, the high-wall pores allow maintaining a greater concentration of $\mathrm{H}^{+}$ions during the cathodic semireaction, regardless of the ions present in the solution, leading to a balance in the process. Meanwhile, plated samples showing low-wall pores (Fig. 3) allowed a poor concentration of hydrogen ions, which in turn resulted in a depletion affecting the normal process, since the cathodic semi-reaction stopped and, as a consequence, a constant current density could be observed.

The gold-plated samples show, in their characterization by SEM, that if the coating is more homogeneous, without micropores, the corrosion is slower. However, it is possible that incipient micropores originate localized detinning (Fig. 4).

Broadly speaking, the aluminum plating showed a greater layer continuity, with localized attack; only a few areas of the coupon showed lacquer detachment which compromised the tin layer, specifically in areas where the lacquer film presented scratching flaws. Hence, deterioration is more homogeneous in this case, providing a higher corrosion resistance against sugar food products. 


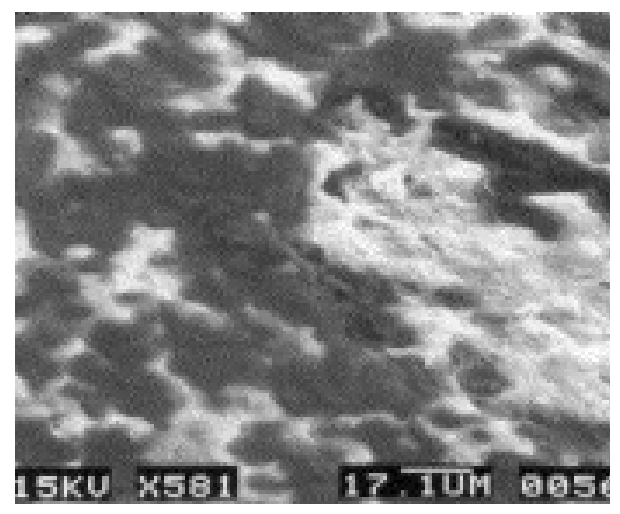

Fig. 3. Detail of gold plating porosity with localized attack on the passivation layer and surface detinning (SEM X 581)

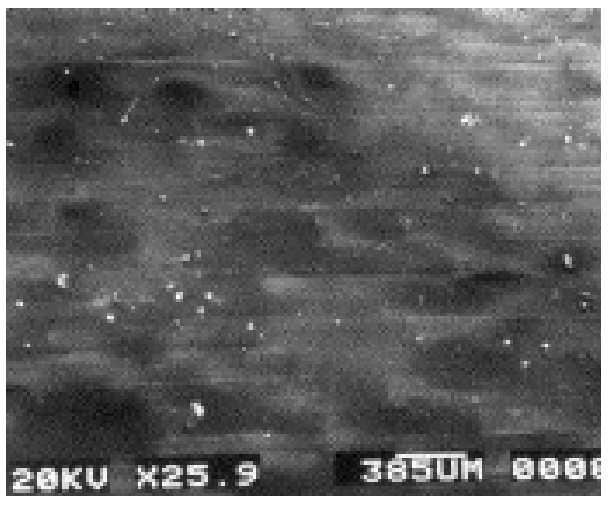

Fig. 4. Localized detinning (dark) under protective lacquer layer (SEM X 25.9)

\section{Conclusions}

The following conclusions from the experimental work and observations made could be drawn:

The stabilization potential having a value close to tin means that the tinplate degradation has compromised in some degree the alloy layer. The opposite means that the presence of tin on the surface is more significant and, therefore, the degradation is much lower.

The attack by the sugar food product is more severe on gold-plated tinplates than that observed on aluminum coated-samples, where the main mechanism of damage is produced by the lacquer pores and their coalescence, even exposing the tinplate surface and increasing therefore the corrosion susceptibility of the other container's substrates. 
The higher walls of the pore, associated with the thickness of the lacquer layer, causes amounts of the electrolyte to be locked inside, creating local deficits in the presence of protons, which means a blockage of the cathodic semi-reaction of the process (proton discharge). This would explain the lower corrosion values observed in tinplates having aluminum plating.

There is a correlation between electrochemical measurements of tinplates and lacquers showing the greatest corrosion attack when characterized against electron microscopy observations, which confirms a more intense surface deterioration by pitting and localized detinning.

The experimental evaluation of canning lacquered tinplates shows that the application of electrochemical techniques and electron microscopy observations are valid methods to characterize food/container systems in quality control studies.

Our special thanks are to the Research and Development Institute of Universidad Austral de Chile, Projects PEF-97-08 and S-98-03.

\section{References}

HARRISON, W. \& LANDRIAULT, F. (1990): Electrochemical aspect of tinplate corrosion. Proc. 11th Intl Tinplate Conference, London, pp. 278-285.

HELWIG, E. \& BIBER, H. (1990): The use of the scanning electron microscope in investigating container corrosion by canned foods and beverages. Fd Structure, 9, 195-202.

KAMM, G., KOTCHNER, S. \& VITEK, R. (1988): Corrosion anomalies with light colored fruits in plain tinplate cans produced from aluminum killed continuous cast steels, phase II. American National Can Company, Barrington IL, pp. 41-50.

MANHEIM, S. \& PASSY, N. (1982): Internal corrosion and shelf-life of food cans and methods of evaluation. CRC Critical Review in Food Science and Nutrition, 7 (4), 371-407.

PATTIASINA, J. \& HERTEGH, A. (1992): The effect of passivation and storing on epoxy-phenolic lacquers adhesion. Proc. 12th International Tinplate Conference, London, pp. 72-80.

ZUMELZU, E. \& CABEZAS, C. (1995a): Corrosion behavior of tinplate cans in an acetic acetate medium. Alimentos, 8, 1-4.

ZUMELZU, E. \& CABEZAS, C. (1995b): Observations on influence of microstructure on electrolytic tinplate corrosion. Materials Characterization, 34 (2), 143-148.

ZUMELZU, E. \& CABEZAS, C. (1996a): Influence of tinplate structure on its electrochemical performance in a citric-citrate medium. J. Sci. \& Ind. Res., 55, 274-276.

ZUMELZU, E. \& CABEZAS, C. (1996b): Correlation between microstructure and corrosion performance of electrolytic tinplate. Protect. Metals, 32 (2), 190-193. 